\title{
Breeding biology of the Green-backed Tit (Parus monticolus) in southwest China
}

\author{
Ping Ye ${ }^{1}$, Xiaogang Yao ${ }^{1,2}$, Jianli Bi ${ }^{1}$, Guangrong $\mathrm{Li}^{2}$, Wei Liang ${ }^{1}$ and Canchao Yang ${ }^{1 *}$ (i)
}

\begin{abstract}
Studies on breeding biology enable us to broaden our understanding of the evolution of life history strategies. We studied the breeding biology of the Green-backed Tit (Parus monticolus) to provide comprehensive data on nest and egg characteristics, parental behavior throughout egg laying and nestling periods, and reproductive outcome. Our study reveals adaptive behavioral patterns and reproductive strategies for P. monticolus.
\end{abstract}

Keywords: Clutch size, Coordination, Egg incubation, Nestling feeding, Trade-off

\section{Correspondence}

Avian life history is an important field in ecological research and contributes to the development of life history theory (Partridge and Harvey 1988). However, genetic studies are now favored by researchers who can exploit powerful molecular techniques. In contrast, life history studies-the crucial phenotypes for interpreting the patterns of genome sequences-are relatively rare in birds ( $\mathrm{Lu} \mathrm{2015).} \mathrm{The} \mathrm{Green-backed} \mathrm{Tit} \mathrm{(Parus}$ monticolus) is a small forest passerine distributed from the west Himalayans to south central Vietnam and Taiwan Island of China. To date, several studies have been conducted on this species (e.g., Ye et al. 2019). However, not much information is available about the species' most basic reproductive characteristics and behavior, except for a brief field observation-based description of the breeding habits of $P$. monticolus by Li (1988), which included egg characteristics, incubation time, and feeding condition. Shiao et al. (2009) also explored the relationship between the difference in parental food distribution and nestling size, but they studied the Taiwanese subspecies. Therefore, there is still a dearth of detailed reproductive information about $P$. monticolus.

${ }^{*}$ Correspondence: ccyang@hainnu.edu.cn

${ }^{1}$ Ministry of Education Key Laboratory for Ecology of Tropical Islands, College of Life Sciences, Hainan Normal University, Haikou 571158, China

Full list of author information is available at the end of the article
We studied about 200 nests of $P$. monticolus in southwest China using detailed survey and a large amount of video monitoring (2,30,296 $\mathrm{min})$ and investigated information on nest building and egg laying behavior, nest and egg characteristics, incubation and brooding behavior, and reproductive outcome. The aim of this study is to provide complete, up-to-date information on breeding biology for $P$. monticolus, which will form a scientific theoretical basis for related research and protection of the species in the future.

P. monticolus is an East Asian montane passerine that is mainly distributed in south and southeast of Tibet of China, and southwest to central China. It is similar in size (body length: 11-13 cm) and morph (Additional file 1: Figure S1) to the Great Tit (P. major), but its belly and back are bright green in color. The female is morphologically similar to the male, although the black bar on the female's belly is slightly narrower. During breeding periods, the female $P$. monticolus mainly inhabits coniferous forests and mixed coniferous and broad-leaved forests and secondary forests at an altitude of 1200-1300 m (Ye et al. 2019). This study was performed in Kuankuoshui Nature Reserve, Guizhou, Southwestern China $\left(28^{\circ} 06^{\prime}-\right.$ $28^{\circ} 19^{\prime} \mathrm{N}, 107^{\circ} 02^{\prime}-107^{\circ} 14^{\prime} \mathrm{E}$ ). The study area is located in a subtropical moist broadleaf and mixed forest at an altitude of about $1500 \mathrm{~m}$, where the average annual temperature is $13.6^{\circ} \mathrm{C}$, and the average annual total precipitation is $1210 \mathrm{~mm}$ (Yang et al. 2011). original author(s) and the source, provide a link to the Creative Commons licence, and indicate if changes were made. The images or other third party material in this article are included in the article's Creative Commons licence, unless indicated otherwise in a credit line to the material. If material is not included in the article's Creative Commons licence and your intended use is not permitted by statutory regulation or exceeds the permitted use, you will need to obtain permission directly from the copyright holder. To view a copy of this licence, visit http://creativecommons.org/licenses/by/4.0/. The Creative Commons Public Domain Dedication waiver (http://creativeco mmons.org/publicdomain/zero/1.0/) applies to the data made available in this article, unless otherwise stated in a credit line to the data. 
In 2017 and 2018, a total of 124 and 213 nest boxes, respectively, were set up on trees at a height of $3 \mathrm{~m}$ before the onset of the breeding season to attract $P$. monticolus. Nest boxes were checked every two days and daily when nest materials were seen. At the same time, mini-cameras (WJO3, Hisilicon, Shenzhen, Guangdong, China) were set up to monitor egg incubation and nestling feeding behaviors of some $P$. monticolus, and 2,30,296 min of video were recorded for four randomly selected nests. The collected data included nest building time, nest materials, nest size, egg laying date, clutch size, egg size (i.e., egg volume), hatching date, incubation frequencies, fledging date, number of fledglings, body mass and tarsus length of nestlings. Egg volume was calculated by using the formula from Hoyt (1979). The egg length, egg width, and tarsus length were measured with a vernier caliper, accurate to $0.01 \mathrm{~mm}$, while the nestling mass was measured with an electronic scale, accurate to $0.01 \mathrm{~g}$. We used the average egg size of each clutch as a representation of each of the nests. Reproductive success was evaluated by the hatching rate, fledging rate, and nesting success. The hatching rate was calculated as the percentage of hatched eggs, while the fledging rate was calculated as the percentage of fledged nestlings. Nesting success was calculated as the percentage of nests with successful reproduction, wherein successful reproduction referred to nests that had at least one fledged nestling (Yang et al. 2011).

By playing back the video, we recorded and sorted the behavioral data for egg incubation, nestling brooding (keeping nestlings warm), nestling feeding, and feces removal. We summarized egg incubation frequency and time per hour, from 6:00 to 20:00, during the egg incubation stage; daily brooding frequency and daily brooding time; feeding frequency per hour, from 6:00 a.m. to 20:00 p.m.; and daily feeding frequency during the nestling stage. Data analyses were performed using IBM SPSS 25.0 for Windows (International Business Machines Corporation, Armonk, New York, USA). Gaussian regression was used to fit the distribution frequency of clutch size while linear regression was used to fit the coefficient of variation $(\mathrm{CV})$ of nestling body mass or tarsus length with day of life, and feces cleaning frequency with feeding frequency, respectively. Student's $t$ test or the MannWhitney $U$ test was used for comparison of continuous variables. Pearson's correlation, Spearman's correlation, or partial correlation was used for correlation testing. Chi-squared tests were used for comparison of probabilities. Logistic regression was used to fit the growth curve of nestlings. All of the tests were two-tailed and data were presented as mean \pm SD.

In all, $52.5 \%(74 / 141)$ and $54.1 \%(118 / 218)$ of the nest boxes were utilized by P. monticolus in 2017 and 2018, respectively. The outer structure of nests was mainly composed of fresh mosses, and the lining materials were composed of animal hairs. The cup depth and cup diameter of nests were $4.68 \pm 0.65 \mathrm{~cm}$ and $5.29 \pm 0.60 \mathrm{~cm}$, respectively $(n=77)$. The nest building time was $6.70 \pm 7.96$ days $(n=53)$ in 2017 and $11.81 \pm 6.44$ days $(n=95)$ in 2018 . The nest building time in 2018 was significantly longer than that in $2017(Z=-5.757, P$ $<0.01$, Mann-Whitney $U$ test). The earliest egg laying date was recorded in April, with one egg laid each day during egg laying. The egg laying date in 2018 (24 April \pm 12.40 days, $n=59)$ was significantly earlier than that in 2017 (9 May \pm 21.86 days, $n=102)(Z=-5.272, P$ $<0.01$, Mann-Whitney $U$ test). Eggs were oval in shape and had a white base color with fine reddish-brown speckles. Egg size was $1.34 \pm 0.92 \mathrm{~cm}^{3}(n=56)$ in 2017 and $1.32 \pm 0.10 \mathrm{~cm}^{3}(n=93)$ in 2018 , with no significant difference between the 2 years $(t=1.51, \mathrm{df}=147, P$ $=0.133$, Student's $t$ test), and clutch size was $6.71 \pm 1.45$ $(n=56)$ in 2017 , which was significantly smaller than $7.18 \pm 1.52(n=56)$ in $2018(Z=-1.749, P<0.01$, Mann-Whitney $U$ test). Furthermore, the clutch size decreased with egg laying date in both years (2017: $r$ $=-0.579, P<0.01$; 2018: $r=-0.472, P<0.01$, Spearman's correlation).

Incubation and brooding were performed solely by females. The incubation periods in 2017 and 2018 were $12.15 \pm 1.84$ days and $12.89 \pm 1.70$ days, respectively, with significant difference between the 2 years $(Z=-5.757$, $P<0.01$, Mann-Whitney $U$ test). The daily egg incubation frequency and time from four observed nests had a peak in the medium stage, but the daily nestling brooding frequency and time decreased continuously with the growth of nestlings and disappeared when nestlings were 7-10 days old (Fig. 1). The daily frequency of incubation and brooding changed among different nests, but the daily brooding of these was similar (Fig. 1). Females stayed overnight in nests during incubation and brooding periods. The hourly incubation frequency and time exhibited a similar pattern among nests. At dawn and dusk the frequency was low while the time was high. On the contrary, at daytime the frequency was high while the time was low (Fig. 2).

Eggshells were swallowed or ejected by parents after nestlings hatched and females remained sitting on nests to keep the nestlings warm. The nestling periods lasted $19.30 \pm 1.77$ days $(n=74)$, with no significant difference between 2017 and $2018(t=1.187, \mathrm{df}=72, P=0.248$, Student's $t$ test), and both males and females participated in nestling feeding. The feeding patterns of three observed nests were similar. They increased gradually with the growth of nestlings but decreased in the later growth period before nestlings fledged (Fig. 3). Three 


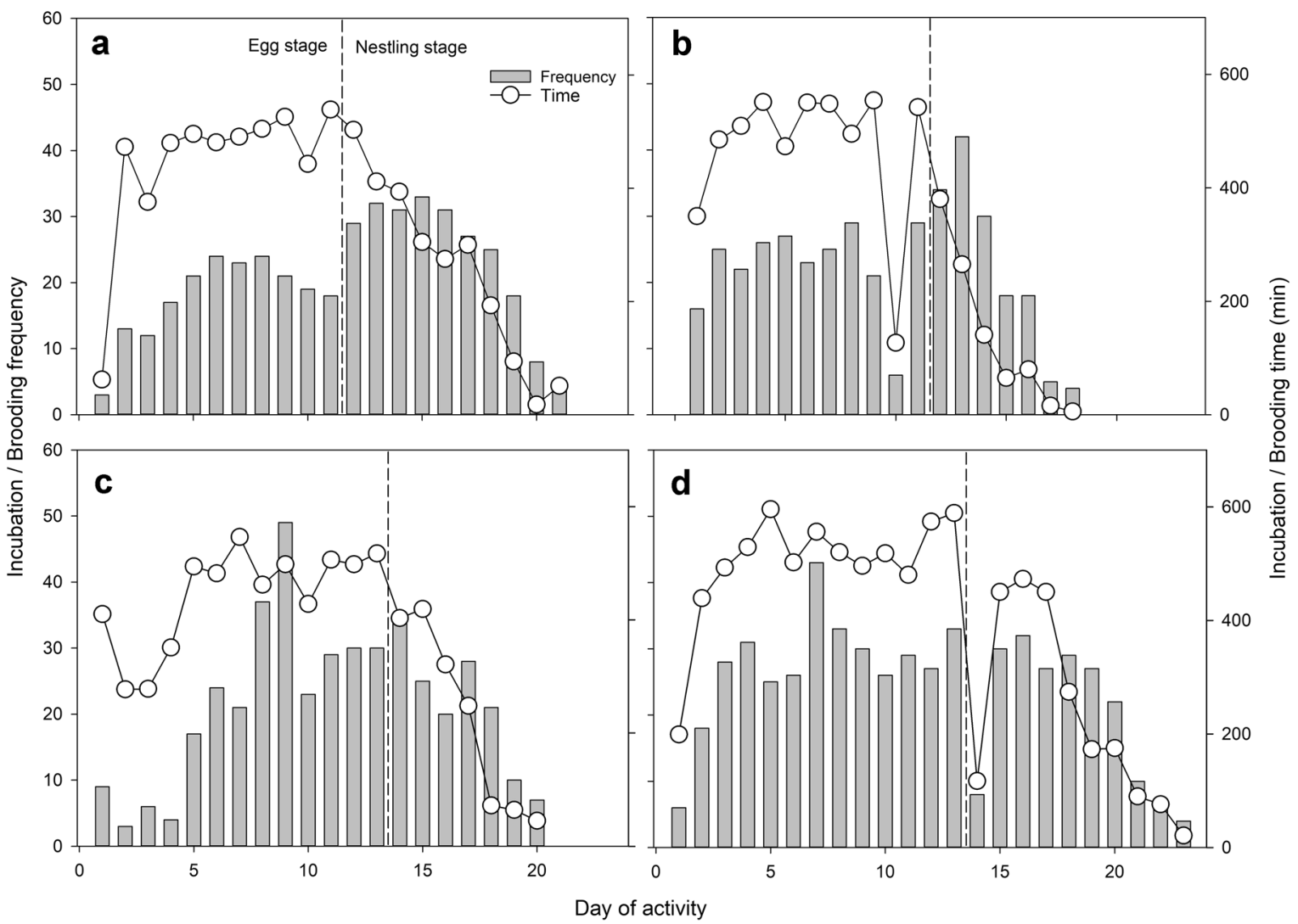

Fig. 1 Daily frequencies and time of egg incubation and nestling brooding in four observed Parus monticolus nests (a-d). The egg and nestling stages are separated by dashed lines

pathways of food delivery during nestling feeding were recorded, including female-to-nestling, male-to-nestling, and male-to-female-to-nestling (Fig. 3). The third pathway existed only in the early stage of nestling feeding period, and the feeding frequencies of the first two pathways between males and females were highly correlated $(r=0.812, P<0.001 ; r=0.712, P<0.001$ and $r$ $=0.795, P<0.001$ for three observed nests respectively, Pearson's correlation; Fig. 3). The hourly feeding frequencies had similar pattern at daytime and dusk with frequencies being stable and decreasing, respectively (Additional file 1: Figure S2). Additionally, feces cleaning frequency increased significantly with the feeding frequency in both male and female parents (male: $r$ $=0.862, P<0.001$, female: $r=0.872, P<0.001$, Pearson's correlation; Additional file 1: Figure S3). The growth curves of body mass and tarsus length of 414 nestlings from 70 nests were both well fitted by logistic regression (Fig. 4), while the CV in body mass and tarsus length within broods decreased with nestling age (body mass vs. nestling age: $-0.497, P<0.01$, tarsus length vs. nestling age: $-0.454, P<0.01$, partial correlation controlling for brood size; Fig. 4). Nestlings looked morphologically similar to the adults on the days before they were going to fledge (Additional file 1: Figure S4).

The total nesting success in $2017(n=74)$ was $66.2 \%$. Nest reproduction failure included predation (10.8\%), desertion at the egg laying $(6.7 \%)$ or incubation $(5.4 \%)$ stage, occupation by other species (8.1\%), and nestlings' death without predation $(2.7 \%)$. The total nesting success in $2018(n=110)$ was $54.2 \%$. Nest reproduction failure included predation $(16.1 \%)$, desertion at the egg laying $(6.8 \%)$ or incubation $(5.1 \%)$ stage, occupation by other species (7.6\%), desertion due to broken nest boxes (1.6\%), and nestlings' death without predation (8.5\%). Nesting success did not differ between the two years $\left(x^{2}=2.70\right.$, $\mathrm{df}=1, P=0.132$, chi-squared test). The hatching rates in 2017 and 2018 were $59.5 \%$ (241 out of 405 eggs) and $57.3 \%$ (428 out of 747 eggs), respectively, with no significant difference between the two years $\left(\mathrm{x}^{2}=0.53, \mathrm{df}=1\right.$, $P=0.492$, chi-squared test). The fledging rates in 2017 and 2018 were $83.9 \%$ (193 out of 230 nestlings) and $70.0 \%$ (305 out of 436 nestlings), respectively, with significant 

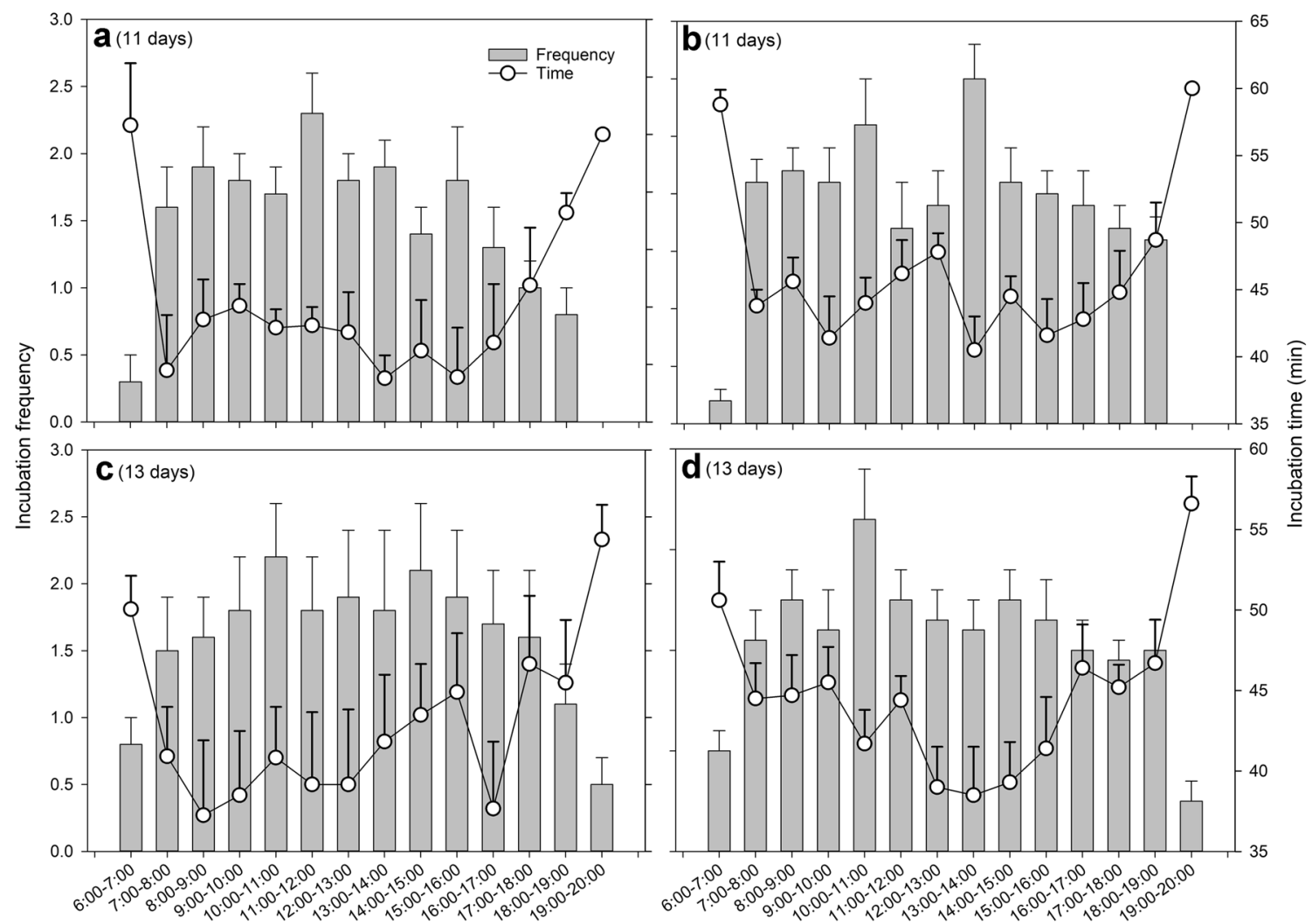

Time inverval

Fig. 2 Egg incubation frequencies and time per hour, from 6:00 to 20:00, of four observed Parus monticolus nests (a-d). The number of days for egg incubation is presented in brackets

difference between the two years $\left(\chi^{2}=15.26, \mathrm{df}=1, P\right.$ $<0.01$, chi-squared test).

In this study, we found that some critical breeding parameters were significantly different between years, such as nest building time, laying date, and clutch size. One possible explanation is that the differences in environmental conditions between years affected the availabilities of nesting materials and food resources. The clutch size of $P$. monticolus declined consistently with the egg laying date. This indicated that the clutch size declined with the progress of the breeding period. A previous study has shown that the clutch size was affected by spatial differences (i.e., latitude and altitude) or temporal differences (i.e., seasons) (Gil-Delgado et al. 2005). Seasonal differences are common in cavity-nesting birds, such as the Blue Tit (Cyanistes caeruleus) and Great Tit (Parus major) (Goodenough et al. 2009). Seasonal changes are generally interpreted as a response to the environment, and the clutch size reduction is a strategy used to adapt to seasonal changes, such as food shortages (Gil-Delgado et al. 2005).
Nest attention is the most widely studied aspect of the incubation behavior of birds. A trade-off regarding time allocation between foraging and incubation investment exists in incubating parents because they need to maintain a balance between self-requirements and embryonic development (Cooper and Voss 2013). Female P. monticolus adopted an incubation strategy of high frequency with short duration of every time (Fig. 2), which is similar to Great Tits (Bueno-Enciso et al. 2017). Incubating parents reduce the incubation frequency and prolong the duration of incubation in the late incubation stage because the egg cooling speed changes with embryo development and the heat quantity needed by the embryo increases in the late incubation stage (Drent 1970). However, some studies have found no correlation between the incubation frequency and incubation progress (Matysioková and Remeš 2010). Similarly, we did not find obvious regular changes in the egg incubation stage (Figs. 1,2).

During the nestling stage, the parents are also confronted with a trade-off between foods for either selfrequirements or nestling growth. Like most passerine birds, the brooding in $P$. monticolus is performed by 


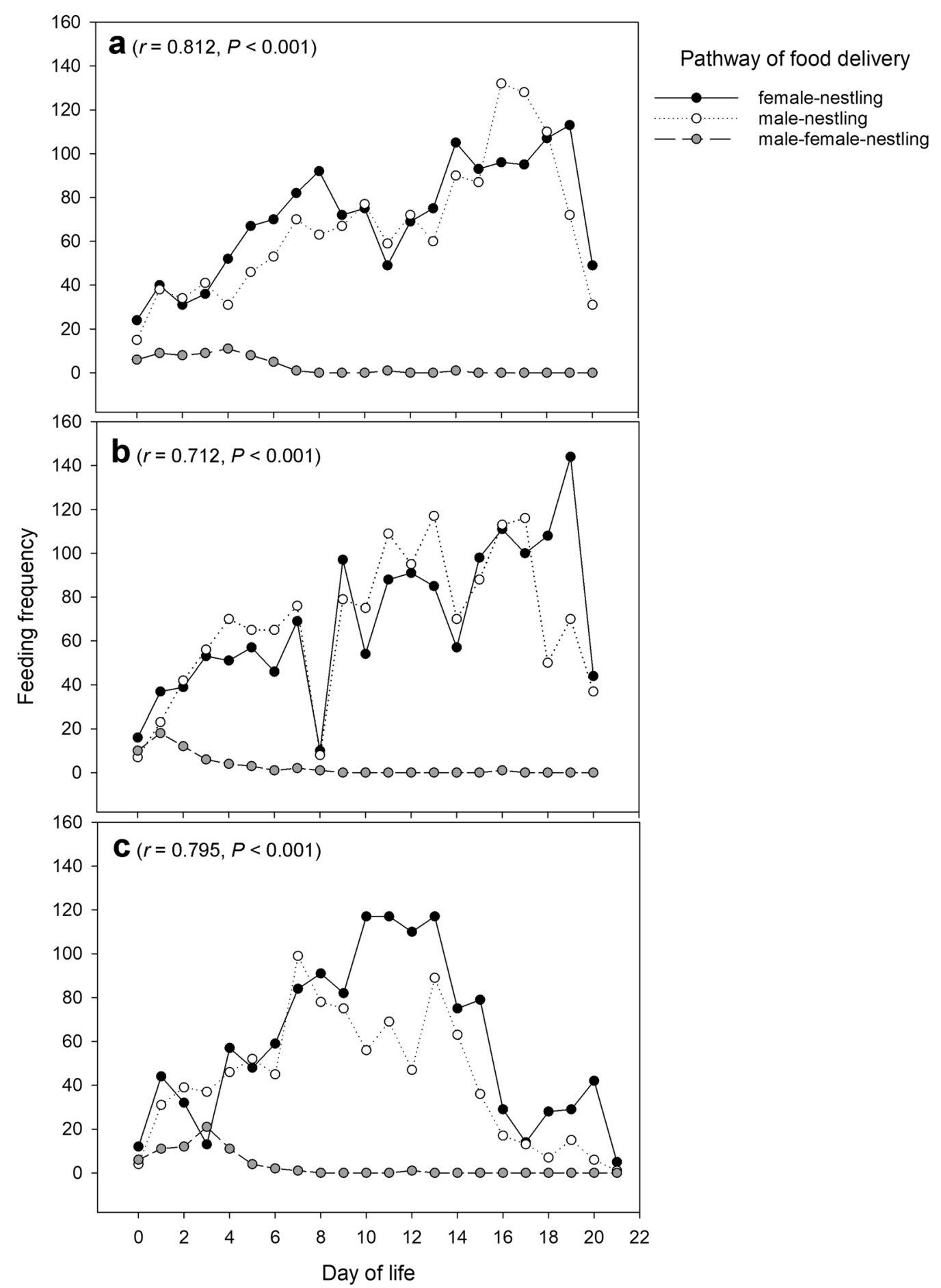

Fig. 3 Three pathways of parental feeding by male and female Parus monticolus from three observed nests (a-c). Three pathways included food delivery from (1) female to nestling, (2) from male to nestling, or (3) from male to female and to nestling. The results of Pearson's correlation in brackets refer to the correlation between the first two pathways (male vs. female) of feeding frequency

females. However, this behavior only occurred in the initial part of the nestling stage and both the brooding frequency and time decreased continuously because the thermoregulation ability of nestlings was developing and their food demands were increasing as they grew (Yu et al. 2016). A male-female-nestling pathway of 

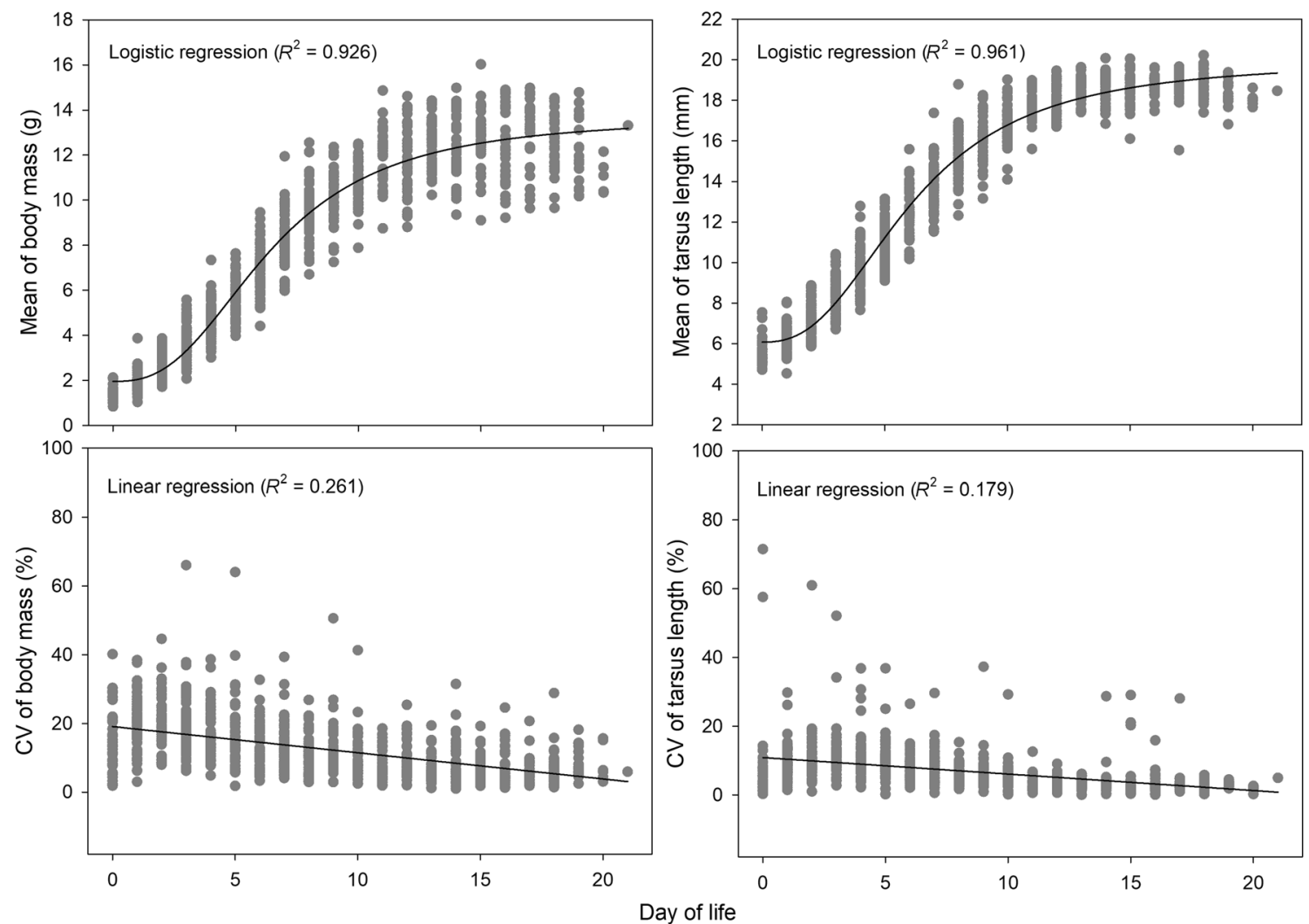

Fig. 4 Nestling growth pattern of 414 nestlings from 70 Parus monticolus nests. Mean and coefficient of variance (CV) were calculated to represent nestling growth and its variance for each nest. The $R$ square of curve fit by logistic or linear regression is provided in brackets

food delivery occurred during the early period of hatchling growth, which indicated that this was a critical time because the hatchlings needed warmth and food simultaneously but the females could not provide both at the same time. Therefore, males cooperated with females to deal with this conflict. After that, male and female parents both provided food. The feeding frequency between the sexes was highly correlated, suggesting a high synchronization of food providing between males and females (Fig. 3). This result was consistent with previous studies showing that monogamous females and males equally participated in nestling feeding (Leffelaar and Robertson 1986).

Feces cleaning is a common but important behavior because it can reduce nest predation and parasite infection. We found that the feces cleaning frequency was highly correlated with feeding frequency in both male and female parents (Additional file 1: Figure S3) because nestling defecation was controlled by parental feeding that the nestlings defecated only after they were fed (Quan et al. 2015). In some cases when nestling defecation was absent, the parents waited and touched the bill or cloaca of nestlings to stimulate defecation (Guigueno and Sealy 2012). This result supported that parents and their nestlings had high coordination to keep the nest clean.

Parents provide food to their nestlings for survival and growth. However, sexual conflict between male and female parents during nestling feeding is a common phenomenon in passerines (Bebbington and Hatchwell 2016). According to the cuckoldry risk hypothesis, males prefer to feed large nestlings, while females prefer to feed small nestlings to minimize their size differences (Dickens and Hartley 2007). Clutch size adjusters tend to distribute food evenly among nestlings, preferentially feeding offspring that are in poor condition, while brood reducers tend to feed larger offspring independently of begging in P. monticolus tensity (Soler 2001). In P. monticolus, both the variation of body mass and the tarsus length of nestlings within clutches decreased with their growth (Fig. 4). As a result, the differences in the body sizes were minimized before the birds fledged. This suggests that $P$. monticolus are clutch adjusters.

In summary, our study not only updates and supplements the biology and natural history of P. monticolus but also reveals some adaptive behavioral patterns and 
reproductive strategies. These findings have important implications for the population conservation and provide relevant evidence for the study of the functional significance of species behavior patterns in the future.

\section{Supplementary Information}

The online version contains supplementary material available at https://doi. org/10.1186/s40657-021-00296-z.

Additional file 1: Figure S1. Photo of a female Parus monticolus incubating in a nest box. Figure S2. Nestling feeding frequencies and time per hour, from 6:00 to 20:00, of four observed Parus monticolus nests (A-D). Figure S3. Relation between diurnal feeding frequency and feces cleaning frequency of nestlings by male and female parents that were summarized from three observed Parus monticolus nests. Figure S4. Photos of Parus monticolus nestlings in different days of life.

\section{Acknowledgements}

We thank the Forestry Department of Guizhou Province and Kuankuoshui National Nature Reserves for support and permission to carry out this study, and are grateful to Yan Cai for assistance with the fieldwork. We also thank the anonymous reviewers for helpful suggestions that improved our manuscript.

\section{Authors' contributions}

CY conceived and designed the study. CY and PY conducted the investigation in the field, analyzed the data and drafted the manuscript. XY, GL and WL assisted the field work. All authors read and approved the final manuscript.

\section{Funding}

Financial support has been provided by Hainan Provincial Natural Science Foundation of China (320CXTD437 and 2019RC189 to CY), National Natural Science Foundation of China (31672303 to CY), and Hainan Provincial Innovative Research Program for Graduates (Hyb2020-48 to PY).

\section{Declarations}

\section{Ethics approval and consent to participate}

The experiments reported here comply with the current laws of China. Fieldwork was carried out under the permission from Kuankuoshui National Nature Reserve, China. Experimental procedures were in agreement with the Animal Research Ethics Committee of Hainan Provincial Education Centre for Ecology and Environment, Hainan Normal University (Permit No. HNECEE-2011-001).

\section{Competing interests}

The authors declare that they have no competing interests.

\section{Author details}

${ }^{1}$ Ministry of Education Key Laboratory for Ecology of Tropical Islands, College of Life Sciences, Hainan Normal University, Haikou 571158, China. ${ }^{2}$ Kuankuoshui National Nature Reserve, Suiyang 563300, Guizhou, China.

Received: 25 August 2021 Accepted: 1 November 2021 Published online: 09 November 2021

\section{References}

Bebbington K, Hatchwell BJ. Coordinated parental provisioning is related to feeding rate and reproductive success in a songbird. Behav Ecol. 2016;27:652-9.

Bueno-Enciso J, Barrientos R, Sanz JJ. Incubation behaviour of Blue Cyanistes caeruleus and Great Tits Parus major in a Mediterranean habitat. Acta Ornithol. 2017:52:21-34.

Cooper CB, Voss MA. Avian incubation patterns reflect temporal changes in developing clutches. PLoS ONE. 2013;8:e65521.

Dickens M, Hartley IR. Differences in parental food allocation rules: evidence for sexual conflict in the blue tit? Behav Ecol. 2007;18:674-9.

Drent RH. Functional aspects of incubation in the Herring Gull. Behav Suppl. 1970;17:S1-132.56.

Gil-Delgado JA, Marco E, Paredes M, Vives-Ferrandizl C. Seasonal clutch size variation of multi-brooded bird species: comparisons between breeding season and latitudes. Ibis. 2005;147:206-12.

Goodenough AE, Elliot SL, Maitland DP, Hart AG. Variation in the relationship between lay date and clutch size in three cavity-nesting woodland passerines. Acta Ornithol. 2009;44:27-36.

Guigueno MF, Sealy SG. Nest sanitation in passerine birds: implications for egg rejection in hosts of brood parasites. J Ornithol. 2012;153:35-52.

Hoyt DF. Practical methods of estimating volume and fresh weight of bird eggs. Auk. 1979;96:73-7.

Leffelaar D, Robertson RJ. Equality of feeding roles and the maintenance of monogamy in tree swallows. Behav Ecol Sociobiol. 1986;18:199-206.

Li HC. An observed on breeding habits of the green-backed tit (Parus monticolus). Sichuan J Zool. 1988;7:30-1.

Lu X. Hot genome leaves natural histories cold. Science. 2015;349:1064.

Matysioková B, Remeš V. Incubation feeding and nest attentiveness in a socially monogamous songbird: role of feather colouration, territory quality and ambient environment. Ethology. 2010;116:596-607.

Partridge L, Harvey PH. The ecological context of life history evolution. Science. 1988;241:1449-55.

Quan RC, Li H, Wang B, Goodale E. The relationship between defecation and feeding in nestling birds: observational and experimental evidence. Front Zool. 2015;12:21.

Shiao M-T, Chuang M-C, Wang Y. Differential food distribution by male and female Green-backed Tits (Parus monticolus) in relation to nestling size. Auk. 2009;126:906-14.

Soler M. Begging behaviour of nestlings and food delivery by parents: the importance of breeding strategy. Acta Ethol. 2001;4:59-63.

Yang C, Cai Y, Liang W, Antonov A. Breeding biology of the golden parrotbill (Paradoxornis verreauxi) (Aves: Timaliidae) in southwestern China. J Nat Hist. 2011;45:1817-22.

Ye P, Yang C, Liang W. Nest site availability and niche differentiation between two cavity-nesting birds in time and space. Ecol Evol. 2019;9:11904-10.

Yu J, Wang PC, Lu L, Zhang ZW, Wang Y, Xu JL, et al. Diurnal brooding behavior of long-tailed tits (Aegithalos caudatus glaucogularis). Zool Res. 2016;37:84-9.

Ready to submit your research? Choose BMC and benefit from

- fast, convenient online submission

- thorough peer review by experienced researchers in your field

- rapid publication on acceptance

- support for research data, including large and complex data types

- gold Open Access which fosters wider collaboration and increased citations

- maximum visibility for your research: over $100 \mathrm{M}$ website views per year

At BMC, research is always in progress.

Learn more biomedcentral.com/submissions 